\title{
DATA COMEMORATIVA COMO PRETEXTO PARA TRABALHO INTERDISCIPLINAR
}

\author{
Um galo sozinho não tece uma manhã: \\ ele precisará sempre de outros galos. \\ De um que apanhe esse grito que ele \\ e o lance a outro; de um outro galo \\ que apanhe o grito de um galo antes \\ e o lance a outro; e de outros galos \\ que com muitos outros galos se cruzem \\ os fios de sol de seus gritos de galo, \\ para que a manhã, desde uma teia tênue, \\ se vá tecendo, entre todos os galos. \\ (Joao Cabral de Melo Neto)
}

\author{
Idonézia Collodel Benetti \\ João Paulo Roberti Junior \\ Universidade Federal de Santa Catarina - UFSC (Brasil) \\ Cristiane Deon Busnello \\ Renilda Ribeiro Ferrugem \\ Secretaria do Estado da Educação de Santa Catarina - SED (Brasil)
}

\begin{abstract}
Resumo. Este é um relato de experiência de um trabalho interdisciplinar realizado em uma escola da Rede Estadual de Ensino de Santa Catarina, em Florianópolis. Foram participantes 230 alunos do Ensino Fundamental I e II e a interdisciplinaridade contemplou os conteúdos das disciplinas de Artes, Inglês e Matemática. O objetivo da proposta foi provocar mais interesse e participação dos alunos no cotidiano escolar, ao colocá-los no centro do processo, numa relação estreita com a aprendizagem interdisciplinar. Os assuntos e a integração entre as disciplinas tiveram a extensão de um bimestre letivo. O percurso metodológico comtemplou: a formação de uma equipe interdisciplinar com troca de informações sobre o conteúdo de cada professor; participação dos alunos no planejamento e desenvolvimento das atividades; elaboração de exercícios e trabalhos. Os trabalhos tiveram seu desfecho com uma exposição realizada no espaço físico escolar. A experiência interdisciplinar mostrou que os alunos ficam mais envolvidos, motivados e dispostos, e se engajam com mais prazer nos trabalhos de sala de aula, quando, além do apoio necessário e do incentivo à autodescoberta, existe: a) trabalho colaborativo - ajuda mútua; b) respeito, confiança e empatia; c) responsabilidade para fazer escolhas sobre o quê e como aprender; d) aumento na capacidade de resolver problemas; e) possibilidade para desenvolver cada vez mais o pensamento em profundidade. Ainda, observou-se que a interdisciplinaridade provocou experiências de aprendizagem pessoais relevantes e memoráveis também para os professores. Docentes e discentes evitaram soluções simples e buscaram o movimento da experiência pessoal atrelada à experiência coletiva.
\end{abstract}

Palavras-chave: Interdisciplinaridade, motivação, engajamento, aprendizagem. 


\title{
COMMEMORATIVE DATES AS AN EXCUSE FOR AN INTERDISCIPLINARY WORK
}

\begin{abstract}
This is a report about an interdisciplinary experience carried out in a state school in Florianópolis, Santa Catarina. During two month, 230 students from an elementary school participated in an interdisciplinarity project, which was intertwined with contents of Arts, English and Mathematics. The objective was to provoke more interest and participation of the students in the school routine, placing them at the center of teaching-learning process and, at the same time, in close relation with the interdisciplinary procedures. The methodological procedures included: establishment of an interdisciplinary team work for information exchange about the content of each teacher; student's participation in the planning and development of activities; elaboration of exercises and works. The whole work had its end result with an exhibition realized in the school physical space. The interdisciplinary experience showed that students become more involved, motivated and willing, and engage with more pleasure in classroom work when, in addition, to the necessary support and encouragement of selfdiscovery, there is the presence of: a) collaborative work - mutual help; b) respect, trust and empathy; c) responsibility to make choices about what and how to learn; d) increased ability to solve problems; e) possibility to develop more and more in-depth thinking. Furthermore, it was observed that interdisciplinarity sponsored relevant and memorable personal learning experiences for teachers as well. In a project such that, teachers and students avoided simple solutions and sought the movement of personal experience tied to the collective experience.
\end{abstract}

Keywords: Interdisciplinarity, motivation, engagement, learning.

\section{FECHAS COMEMORATIVAS COMO EXCUSA PARA UN TRABAJO INTERDISCIPLINARIO}

Resumen. Este es un relato de experiencia de un trabajo interdisciplinario realizado en una escuela de la Red Estatal de Enseñanza de Santa Catarina, en Florianópolis. Durante dos meses, 230 estudiantes participaron en un proyecto, que se entrelazó con contenidos de plástica, inglés y matemáticas. El objetivo fue promocionar un mayor y participación en los alumnos en su día a día escolar, al colocarlos en el centro del proceso, a través de una relación estrecha con el aprendizaje interdisciplinario. El camino metodológico contempló: la formación de un equipo interdisciplinario con intercambio de información sobre el contenido de cada profesor; participación de los alumnos en la planificación y el desarrollo de las actividades; la elaboración de ejercicios y trabajos. Los trabajos tuvieron su desenlace con una exposición realizada en el espacio físico escolar. La experiencia interdisciplinaria mostró que los alumnos están más involucrados, motivados y dispuestos y se involucran con más placer en los trabajos de aula, cuando, además del apoyo necesario y del incentivo a la auto descubierta, existe: a) trabajo colaborativo - ayuda mutua; b) respeto, confianza y empatía; c) responsabilidad para hacer elecciones sobre qué y cómo aprender; d) aumento de la capacidad para resolver problemas; e) posibilidad para desarrollar cada vez más el pensamiento en profundidad. Se observó que la interdisciplinariedad patrocinó experiencias de aprendizaje personales relevantes y memorables también para los profesores. Docentes y discentes evitaron soluciones simples y buscaron el movimiento de la experiencia personal vinculada a la experiencia colectiva.

Palabras clave: Interdisciplinariedad, motivación, compromiso, aprendizaje.

\section{Considerações iniciais}

Não é natural para uma criança, que está descobrindo o mundo ao seu redor, separar suas atividades em disciplinas compartimentalizadas. A curiosidade dos jovens alunos não é e não deve limitar-se a uma determinada categoria de assuntos, o que é incompatível com uma compartimentalização dos processos de aprendizagem. Da 
mesma forma, o interesse que os adolescentes assumem com seu próprio desenvolvimento e com problemas sociais não pode ser dividido em disciplinas.

A fim de proporcionar aos alunos um incentivo para aprender, educar-se, preparar-se para aplicar, no cotidiano, o conhecimento que eles adquirem na escola, eles devem receber uma escolaridade que está em sintonia com seus interesses, suas abordagens naturais e com as situações da vida real. O conteúdo da educação deve, portanto, ser descompartimentalizado, já que o ser humano tende a valorizar um indivíduo coeso e integrado. Assim, a fragmentação dos conteúdos certamente não é o caminho ideal para alcançar essa coesão e essa integração da personalidade. Vale realçar que é muito mais relevante evitar a compartimentalização da experiência da aprendizagem e a especialização precoce e oferecer, à criança e ao adolescente, experiências de aprendizagem unificadoras e uma compreensão integral da realidade.

Muito se tem ouvido falar no termo "interdisciplinaridade", bem como nos benefícios advindos de sua aplicação. É fato que hoje muitas escolas e professores têm escolhido trabalhar norteados por parâmetros interdisciplinares, com a finalidade de encontrar maneiras de interligar mais de uma disciplina em torno de um mesmo assunto e, assim, ter uma oportunidade interessante, dinâmica e emocionante de estimular o cotidiano da sala de aula.

Por interdisciplinaridade entende-se o emprego de várias disciplinas no exame de um tema específico, operando em conjunto dentro de um determinado momento histórico e cultural; é a fusão resultante da mistura e/ou integração de ideias trazendo diferentes oportunidades ao convidar os alunos para integrar conceitos, teorias, métodos e ferramentas de duas ou mais disciplinas, com a finalidade de aprofundar sua compreensão sobre um determinado tema (Caroni, 2013, Mon'im e Al-Zyoud, 2015). Neste cenário, está encapsulada a provocação da curiosidade natural dos alunos, que acabam desenvolvendo as habilidades necessárias para, gradativamente, conduzir seus trabalhos e mostrar progressiva independência na aprendizagem.

No ensino interdisciplinar, os educadores aplicam métodos e linguagem de mais de uma disciplina acadêmica para examinar um tema, uma questão, um problema, tópico ou experiência. A principal característica do trabalho interdisciplinar é a integração de noções e princípios orientadores de várias disciplinas para formar sistematicamente um quadro de análises mais completo e coerente, que possa oferecer uma compreensão mais rica da questão em foco (Brooks, 2017).

Métodos interdisciplinares trabalham para criar conexões entre disciplinas tradicionalmente discretas, como matemática, ciências, estudos sociais, história, artes e línguas. Trabalhar com currículo integrado, e ajudar os alunos a assumir o controle de sua própria aprendizagem, torna-se uma realização para os professores (Roberti, Wilhelm, Deon e Collodel-Benetti, 2016). É como se eles tivessem comprado um novo par de lentes, que os auxiliou a enxergar o ensino muito mais emocionante e ajudou a olhar para frente e para o futuro, estimulando todos os envolvidos ao entusiasmo. Além do mais, o suporte social do trabalho em conjunto pode proporcionar a descoberta de novos interesses e técnicas de ensino que revitalizaram o cotidiano da sala de aula (Lenoir, Hasni e Froelich, 2015).

Este fenômeno, que alberga o aprofundamento da compreensão e envolve a instrução interdisciplinar, traz a demanda por múltiplas capacidades - estética, social, analítica, etc. - e promove a preparação para resolver problemas, criar produtos e fazer perguntas, que vão além das perspectivas disciplinares individuais. Pesquisas mostram que a interdisciplinaridade promove a ampliação das fronteiras do conhecimento 
convencional de forma exponencial e, portanto, deve ser considerada na vanguarda da investigação acadêmica (Nikitina, 2006, Van Rijnsoever e Hessels, 2011).

Os estudos interdisciplinares deveriam estar presentes também no ensino superior, pois ao dar aos alunos a oportunidade de contrabalançar disciplinas, novas ligações são forjadas e contribuições importantes são feitas para o mundo do ensino superior e além (Gruenwald, 2014). Isso, porque os alunos, independente de seu nível de escolarização, são capazes de combinar várias disciplinas e buscar diferentes maneiras de pensar sobre o mesmo problema ou assunto. É um estilo revolucionário de aprendizagem que encoraja a colaboração interdisciplinar, permite que os alunos desenvolvam habilidades de pensamento crítico e apresenta muitas oportunidades de crescimento do "mundo real". Portanto, a escola deve preparar os alunos para entender as realidades do mundo contemporâneo, uma vez que a humanidade enfrenta problemas que desafiam a sobrevivência e que não podem ser abordados no contexto estreito de uma única disciplina. Esses problemas exigem compreensão mútua e coordenada entre disciplinas, nações, povos e ideologias.

Este artigo dá conta de uma iniciativa que levou professores, alunos e a instituição a formarem uma equipe de trabalho, que englobou: a) a listagem do conteúdo a ser abordado, b) o planejamento das atividades - incluindo também uma exposição, que teve o apoio da direção da escola -, c) a motivação conjunta dos envolvidos no processo, etc. Formou-se, assim, um grupo interdisciplinar composto por pessoas, com formação em diferentes áreas do conhecimento (disciplinas), com diferentes conceitos, termos, métodos e dados organizados por um esforço comum, trabalhando em torno de um problema comum, com intercomunicação contínua.

A possibilidade de oferecer oportunidades reais de desenvolvimento profissional aos professores apresenta-se desafiadora no sentido de compreender o emprego e integração de várias disciplinas no estudo de um tema específico, operando em conjunto dentro de um determinado momento histórico e cultural. Nesse sentido, interessam os aspectos do fazer em sala de aula que afetam as práticas interdisciplinares na escola, relacionando e tensionando a práxis escolar cotidiana, na maioria das vezes ditada por currículos que reúnem e estruturam "... o conhecimento que deverá ser compartilhado, reproduzido ou produzido nos estudantes sob a ordem de um determinado formato" (Sacristán, 2013, p. 262), sendo geralmente organizados em domínios, ou disciplinas acadêmicas tradicionais, que geram listagens de conteúdos, promovendo, em muitos casos, o engessamento do professor.

Então, é fundamental a aproximação e o diálogo entre professores para aprofundar o debate acerca do papel dos docentes no processo de ensino/aprendizagem, em face da possibilidade do trabalho interdisciplinar, uma vez que, a despeito dos muitos esforços e das pesquisas relacionadas à interdisciplinaridade, modelos mais tradicionais de currículos acadêmicos, social e historicamente construídos, e legitimados por várias esferas, - Estado, academia, escola, mercado de trabalho, etc., - continuam ditando e/ou influenciando a prática docente.

Com este trabalho buscou-se valorizar a parceria do trabalho docente, com a finalidade de promover o comprometimento coletivo dos professores na melhoria da qualidade integrada das aulas e, ainda, provocar mais interesse e participação dos alunos no cotidiano escolar. Então, a proposta mostrou-se tentadora, já que oferecia a possibilidade de presentear os alunos com um trabalho coeso, mostrando as possibilidades de elaboração de novos enfoques metodológicos para a resolução de problemas. 
Dessa maneira, este cenário descortinava-se acenando para a valorização do aprendizado interdisciplinar por várias razões. Uma delas foi a perspectiva de reconhecimento dos diversos interesses e talentos, alguns dos quais tendem a permanecer invisíveis em cursos disciplinares individuais. A expectativa de ter a criatividade dos alunos valorizada ao máximo, em todos os trabalhos realizados nas disciplinas em questão, e não somente na disciplina de Arte, mostrou-se inspiradora e, sem dúvida, atraiu os professores.

Outra razão importante, que atraiu os professores, foi o convite para identificar o que os estudantes sabiam, e o que eles gostariam de saber sobre o assunto em pauta. A ideia de provocar e estimular os alunos para buscar, e encontrar, novas fontes de informação relevantes, muitas vezes fora da disciplina primária, considerada como apoio inicial dos professores, serviu como agente revitalizador da práxis. A esperança concentrava-se em fazer com que os alunos reforçassem seu papel crescente como agentes de sua própria aprendizagem e encontrassem oportunidades para refletir sobre sua própria experiência e vivência, numa atmosfera que não permitia que fossem apenas expectadores dos assuntos abordados na sala de aula, mas que, ao contrário, evitassem as habituais "decorebas" e práticas de repetição das informações recebidas.

A busca de uma visão intelectualmente rigorosa do conhecimento foi um elemento igualmente importante e desafiador, que estimulou o corpo docente. $\mathrm{O}$ que desafiava era a possibilidade de oferecer, aos alunos, a oportunidade de apreciar a natureza do conhecimento em disciplinas específicas e, além disso, ter também uma visão da coesão e da complementaridade dos vários campos de estudo, em momentos em que eles pudessem apreciar as semelhanças e diferenças entre os modos particulares de como as diferentes disciplinas lançam luz sobre o mundo.

\section{Metodologia implicada: tecendo a Interdisciplinaridade}

Com base nos benefícios da interdisciplinaridade para o desempenho acadêmico, esta pesquisa, de natureza observacional, exploratória e de abordagem qualitativa, buscou captar as ações e reações dos alunos de uma instituição pública da Rede Estadual de Ensino da Secretaria de Educação do Estado de Santa Catarina e, também, quais foram as circunstâncias em que os eventos observados aconteceram (Danna e Matos, 2006), durante um projeto interdisciplinar desenvolvido em uma escola da periferia de Florianópolis - Santa Catarina - Brasil, que tradicionalmente comemora o dia das mães ${ }^{i}$, convidando os pais/cuidadores e suas famílias para comparecerem a uma festividade nas dependências dessa unidade de ensino.

Dessa tradição, surgiu a iniciativa de agregar esforços entre os professores para trabalhar, interdisciplinarmente, assuntos envolvendo essa comemoração, junto às diversas configurações familiares que fazem parte dessa comunidade escolar. A unidade escolar em questão possui aproximadamente 700 alunos, que frequentam os anos do Ensino Fundamental I e II e o Ensino Médio. Neste recorte, serão relatadas as vivências com os alunos do Ensino Fundamental I e II - duas turmas do $5^{\circ}$. ano matutino e vespertino e aproximadamente 230 alunos dos $6^{\circ}, 7^{\circ}$ e $8^{\circ}$ Anos ${ }^{i i}$, também dos períodos matutino e vespertino - albergando conteúdos de Artes, Inglês e Matemática.

O trabalho ganhou o título "I was born at..." "iii , por ter sido concebido na disciplina de Língua Inglesa. Então, tal qual como os "galos" de João Cabral de Melo Neto, que interagem para tecer "uma manhã", conforme esboçado na epígrafe 
introdutória deste trabalho, objetivos comuns de aprendizagem foram abordados por mais de um professor, em diferentes aulas e disciplinas, na tentativa de melhor compartilhar os conteúdos selecionados para desenvolver os trabalhos em sala de aula.

É importante enfatizar que, nesse momento do ciclo vital, os alunos estão entrando na puberdade, ou fazendo a transição da puberdade precoce para os meados da adolescência. Este é um período crucial de desenvolvimento social, físico e intelectual pessoal, de incerteza e de muitos questionamentos. Pensando nisso, este trabalho teve, também, como objetivo ajudar os alunos a desenvolver conhecimentos, atitudes e habilidades para participar ativa e responsavelmente em um mundo de inter-relações, que está em constante em mudança. A ideia esteve pautada em colocá-los no centro do processo de uma aprendizagem voltada para a visão holística do conhecimento, com vistas a cultivar o envolvimento deles na construção da informação, numa relação estreita com a aprendizagem interdisciplinar (Huutoniemi, Klein, Bruun e Hukkinen, 2010).

A técnica de amostragem utilizada foi a "Ad Libitum" - uma técnica de registro na qual se realiza uma amostragem à vontade do comportamento, onde são anotados os atos comportamentais que o organismo executa. Optou-se pelo Registro Contínuo Cursivo, por ser um relato sobre o que é presenciado, na sequência em que os fatos de sucedem (Fagundes, 1999), onde foi possível anotar: 1) a localização do sujeito; 2) sua postura e posição; 3) os eventos comportamentais; e, 4) os eventos ambientais (Danna \& Matos, 2006). Apesar de ser "uma amostragem sem limitações sistemáticas de quem e onde amostrar" (Del-Claro, 2004), alguns aspectos foram elencados para serem observados, a saber:

- Capacidade de expressar conceitos importantes, apresentar dados e conclusões por escrito e para seus colegas de equipe e grande grupo;

- Habilidade de ouvir atentamente, esperando pela sua vez para manifestar-se;

- Iniciativa para tomar decisões, pensar de forma crítica e criativa, e sintetizar o conhecimento trabalhado;

- Envolvimento dos professores de outras disciplinas;

- $\quad$ Engajamento e motivação dos alunos na realização de tarefas e durante as aulas;

- Habilidades de pensamento crítico, síntese e pesquisa;

- Desenvolvimento de grupo, da amizade, confiança e ação conjunta e, também, colaboração entre os pares de trabalho;

- Autoconfiança e autoeficácia no compartilhamento da aprendizagem;

- Desenvolvimento de conscientização sobre as responsabilidades com as tarefas e aprendizado individual, em equipe e em ambiente doméstico.

A lista de itens a ser observada foi elaborada pelos professores que trabalharam o projeto e os registros foram realizados, individualmente, em cada tipo de atividade desenvolvida. Ao final do projeto, os professores se reuniram para analisar, avaliar e discutir o conteúdo de cada registro.

Os assuntos e a integração entre as disciplinas tiveram a extensão de um bimestre letivo e envolveram, além das três disciplinas, a escola e os pais dos alunos, no apoio à compra de materiais e ao incentivo nas atividades. As professoras elaboraram 
uma lista com conteúdos a serem trabalhados, sempre respeitando as dificuldades das turmas e o nível de complexidade do assunto abordado, conforme Tabela 1.

Tabela 1

Conteúdo selecionado pelos professores

\begin{tabular}{|c|c|c|}
\hline Artes & Inglês & Matemática \\
\hline $\begin{array}{l}\text { Salvador Dali - documentário } \\
\text { em vídeo e texto sobre o artista. }\end{array}$ & Revisão de números e hora. & Formas geométricas. \\
\hline Cores usadas nas obras de Dali. & $\begin{array}{l}\text { Leitura e interpretação de } \\
\text { texto sobre a "Persistência da } \\
\text { Memória". }\end{array}$ & $\begin{array}{l}\text { Divisão da circunferência } \\
\text { em quatro partes iguais - }\end{array}$ \\
\hline $\begin{array}{l}\text { A "Persistência da Memória" } \\
\text { (conhecendo a obra). }\end{array}$ & interpreta & Guatro guadrantec \\
\hline Releitura da "Persistência da & texto sobre Salvador Dali. & $\begin{array}{l}\text { Divisão dos } 360^{\circ} \text { em doze } \\
\text { partes iguais, para }\end{array}$ \\
\hline Memória”. & $\begin{array}{l}\text { Relógios famosos no mundo. } \\
\text { Tipos de relógios (de pulso, }\end{array}$ & $\begin{array}{l}\text { localização das horas e dos } \\
\text { minutos. }\end{array}$ \\
\hline $\begin{array}{l}\text { Confecção de relógios para } \\
\text { presentear as mães. }\end{array}$ & ampulheta, cronometro, etc.). & $\begin{array}{l}\text { Ângulos formados entre os } \\
\text { ponteiros do relógio. }\end{array}$ \\
\hline $\begin{array}{l}\text { Discussão do filme } \\
\text { "A invenção de Hugo Cabret". }\end{array}$ & $\begin{array}{l}\text { mensagens relacionadas à } \\
\text { data. } \\
\text { Músicas tradicionais com }\end{array}$ & $\begin{array}{l}\text { Confecção de um relógio } \\
\text { com mostrador }\end{array}$ \\
\hline $\begin{array}{l}\text { Releitura de uma cena do filme } \\
\text { "A invenção de Hugo Cabret" }\end{array}$ & letras de Hora/Relógio. & $\begin{array}{l}\text { envolvendo cálculos } \\
\text { matemáticos. }\end{array}$ \\
\hline
\end{tabular}

Nota: Fonte: Acervo dos autores

\section{Resultados}

Com o $5^{\circ}$ ano foi trabalhada a integração de conteúdos de várias áreas. Assim, tendo em vista que o homem começa sua história a partir do seu nascimento, as crianças contaram suas próprias histórias e construíram um mural dos aniversariantes com a data do aniversário de cada uma delas - aqui, foi utilizado o conhecimento matemático aplicado a datas, mostrando a utilidade dos cálculos na vida diária.

Em tempos digitais, muitas crianças do $5^{\circ}$ ano aprenderam a reconhecer as horas em relógios analógicos e, também, aprenderam sobre medida de tempo, resolvendo situações-problema envolvendo cálculos matemáticos. Ainda, trabalharam expressões de tempo (ontem, amanhã, era uma vez, certa vez, algum tempo atrás, etc.), reconhecendo presente, passado e futuro. A produção da compreensão interdisciplinar dos alunos é listada a seguir.

\section{Produção discente}

Arte

- Releituras da obra "A persistência da memória" - salvador Dali;

- Criação/desenho sobre uma cena do filme "A invenção de Hugo Cabret";

- Confecção de relógios para presentear as mães/responsáveis/tutoras. 
Inglês

- $\quad$ Leitura e compreensão de texto sobre a vida e a obra de Salvador dali;

- Elaboração de hipóteses e inferências frente ao desafio de compreender os textos;

- Reconhecimento e nominação de diversos tipos de relógios;

- Descrição de relógios famosos no mundo;

- $\quad$ Elaboração de mensagens para o dia das mães em cartões;

- Leitura, interpretação de músicas tradicionais envolvendo horas e relógios.

\section{Matemática}

- Discussão do filme “A invenção de Hugo Cabret”, relacionando-o à matemática;

- Divisão da circunferência nos quatro quadrantes;

- $\quad$ Divisão dos 3600 em doze partes iguais;

- Manuseio do transferidor - muitos não conheciam e/ou nunca tinham trabalhado;

- $\quad$ Determinação dos ângulos formados entre os ponteiros do relógio;

- Escolha da forma geométrica para confecção dos relógios;

- Confecção de um relógio para a sala de matemática, onde é necessário resolver uma expressão numérica, com números naturais, inteiros e racionais e as operações básicas (adição, subtração, multiplicação, divisão, raiz quadrada e potenciação), para descobrir a hora marcada.

Os trabalhos tiveram seu desfecho com o programa dedicado às mães/tutoras/ responsáveis, no espaço físico da escola, com apresentação e exposição de todos as atividades interdisciplinares realizadas no bimestre, que foram oferecidas a elas como presente. Como parte da programação, o cuidador/tutor deveria "descobrir" qual era o trabalho do seu filho/tutorado. Para isso, deveria observar a hora registrada nos relógios - a pista era o horário do nascimento da criança.

Com a colaboração de toda a escola, realizou-se uma exposição de relógios diferentes (inclusive um deles com o formato dos relógios moles do Dali - Figuras). Os cartões com mensagens alusivas à data foram pendurados em um varal e oferecidos aos homenageados, depois do programa comemorativo.
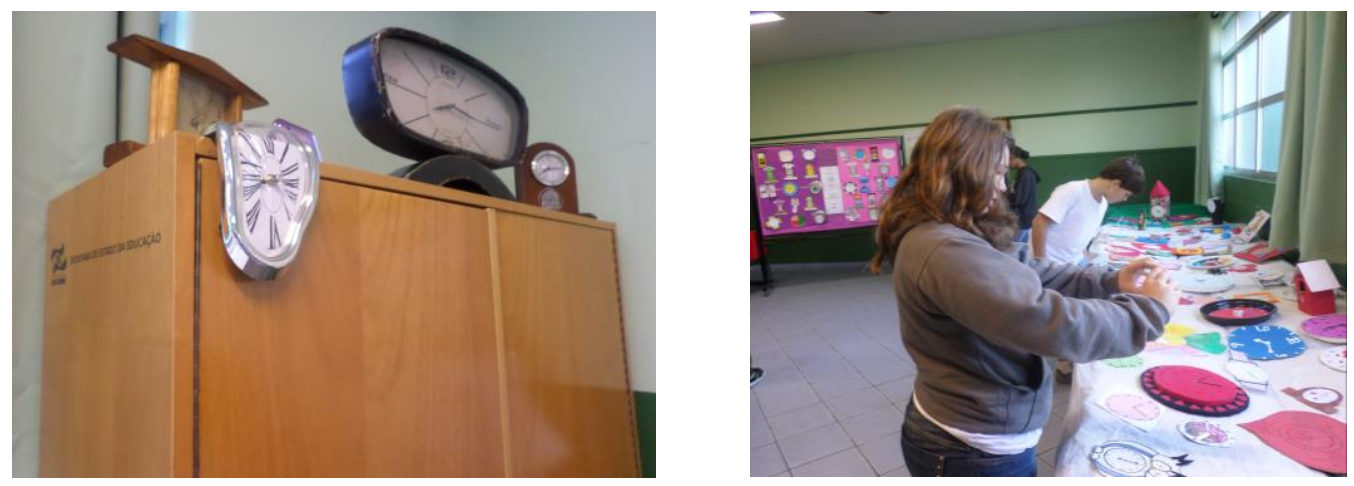

Figuras 1 e 2. Exposição de relógios e de trabalhos dos alunos

Note: Fonte: acervo da escola 

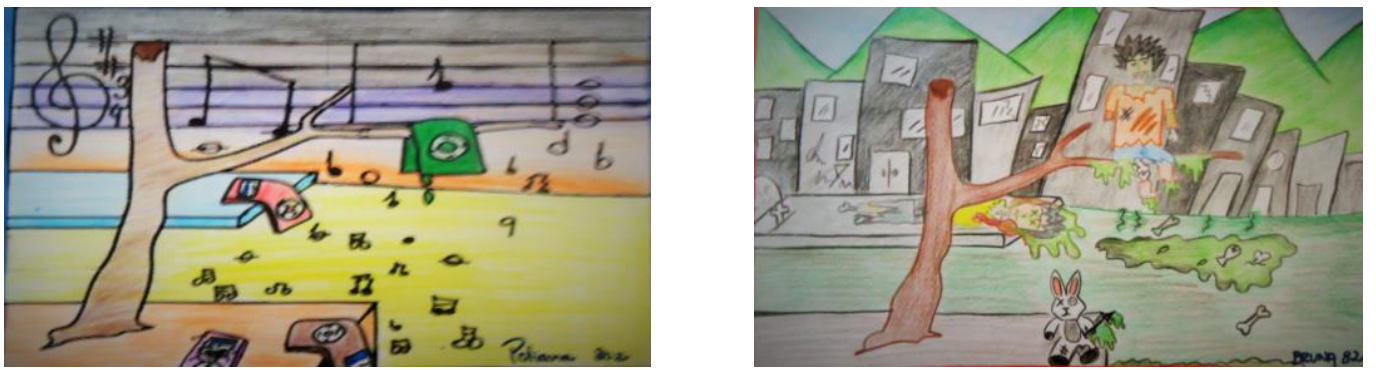

Figuras 3 e 4. Releituras da obra "Persistência da memória" de Salvador Dali Nota: Fonte: acervo da escola

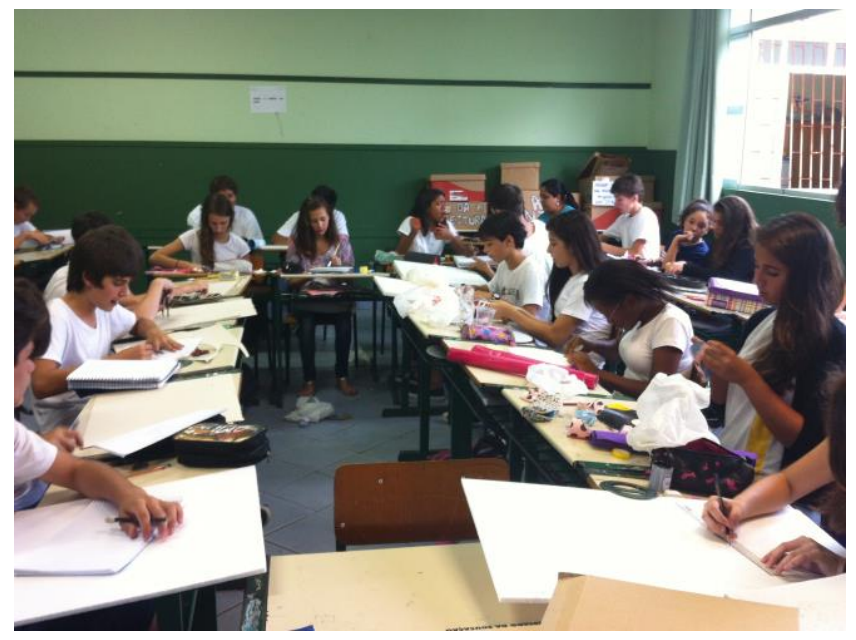

Figura 5. Alunos em processo de elaboração de trabalhos

Nota: Fonte: acervo da escola

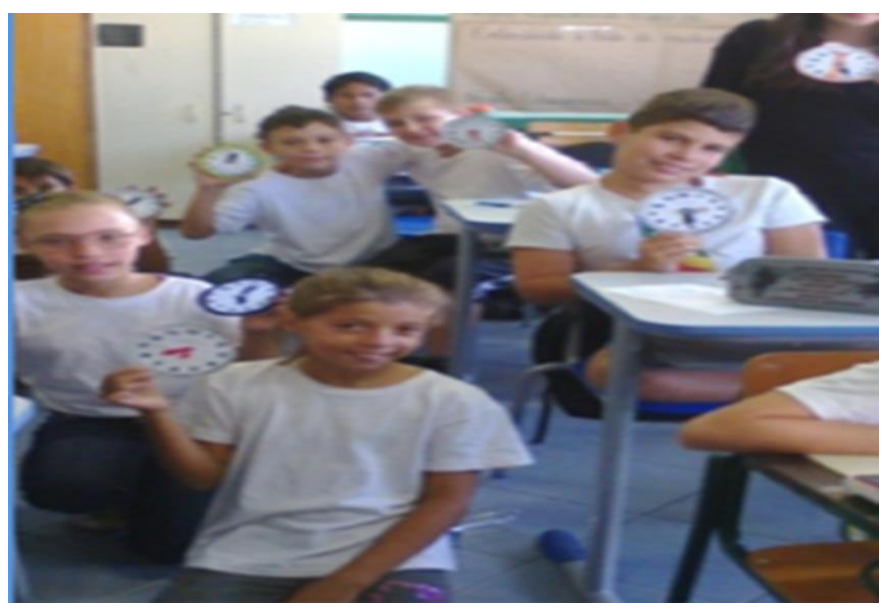

Figuras 6. Alunos do $5^{\circ}$ Ano com relógios elaborados para marcar a hora do nascimento de cada autor.

Nota: Fonte: acervo da escola 


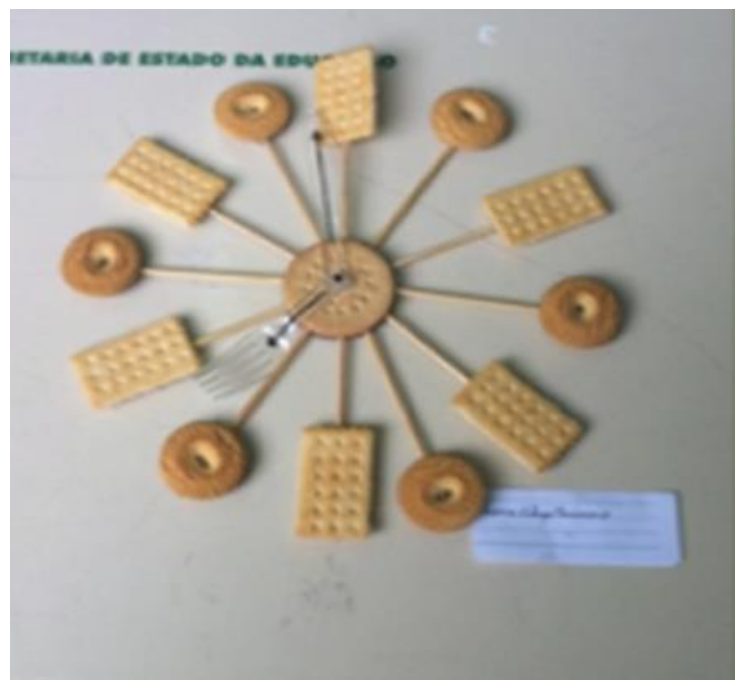

Figura 7. Relógio de bolachas marcando a hora do nascimento do aluno

Nota: Fonte: Acervo da escola

\section{Avaliando a experiência}

Observou-se que, após o trabalho com as aulas integradas, os alunos conseguiam lembrar, e aplicar, com mais facilidade os conceitos gerais utilizados, bem como identificar, avaliar e transferir informações significativas e necessárias para resolver problemas novos, num movimento que envolveu compreensão, transferência de conhecimento, significado e intenção (Haynes, 2014). Este tipo de engajamento e investimento permitiu ao aluno aprender fazendo conexões entre ideias e conceitos em diferentes fronteiras disciplinares.

Os estudantes que aprendem desta maneira são capazes de aplicar em uma disciplina, o conhecimento adquirido em outra disciplina diferente como forma de aprofundar a experiência de aprendizagem. Esse entendimento envolve a capacidade de expressar conceitos importantes, apresentar dados e conclusões por escrito e para um público, bem como aprender a ouvir atentamente, esperando pela sua vez para manifestar-se (Pharo, Davison, McGregor, Warr e Brown, 2014).

Em outras palavras, a aprendizagem é um processo altamente integrado e não deveria ser facilmente separado em domínios ou disciplinas acadêmicas tradicionais, que muitas vezes servem para engessar o professor. A integração de disciplinas promove s aprendizado através de um envolvimento ativo com o seu ambiente e através do engajamento social com outros seres humanos. O que o aluno pode fazer em cooperação hoje ele pode fazer sozinho amanhã (Vygotsky, 1962).

Este fenômeno constitui-se em um processo que alberga a atividade de “Aprender a aprender", onde os alunos aprendem a monitorar e dirigir seu próprio trabalho e aprendizado (Piaget, 1969, Vygotsky, 1962, Bruner, 1960); e, ainda, mostram mais iniciativa para tomar decisões, pensar de forma crítica e criativa, e sintetizar o conhecimento para além das disciplinas, manifestando mais envolvimento e motivação durante as aulas (Lecq, 2016).

Outro aspecto importante, que vale salientar, é que os alunos também veem seus professores trabalhando juntos. O projeto é apresentado como uma equipe e passa uma sensação de que todos estão juntos, construindo a comunidade escolar (Vangrieken, 
Dochy, Raes e Kyndt, 2015). Para os professores, a colaboração foi valiosa e muito empoderadora: eles compartilharam ideias, recursos, conhecimento, alunos e ficaram satisfeitos porque arranjaram e dedicaram tempo e espaço para trabalhar dessa maneira. Ao final, o currículo mostrou-se significativo e rico e os alunos produziram conteúdos igualmente significantes e ricos.

A experiência revelou que uma das chaves para o sucesso na elaboração de um projeto interdisciplinar é fazer muita pesquisa - livros, internet, consulta aos pares de trabalho, etc... Por esta razão, é importante mante-se sempre com olhos abertos e ouvidos atentos aos conteúdos que estão sendo trabalhados. É fundamental continuar procurando e perguntando - há toneladas de recursos que circundam professores e alunos; muitos destes recursos são pouco explorados. Ainda, esta experiência revelou que:

- O fenômeno da aprendizagem acontece melhor com emoção, desafio, apoio necessário; e a autodescoberta precisa e deve ser incentivada sempre, porque a tendência é os alunos tornarem-se pensadores interdisciplinares e abraçarem de forma analítica e criativa novas ideias (DiCamillo e Bailey, 2016);

- A aprendizagem é um processo de descoberta pessoal e uma atividade social, onde o aluno é responsável pelo ato de aprender e pode estar engajado neste processo com prazer (Bestelmeyer, Elser, Spellman, Sparrow, Haan-Amato e Keener, 2015);

- A aprendizagem é mais bem fomentada na coletividade, onde as ideias dos alunos e professores são respeitadas e onde existe confiança mútua, numa atmosfera de empatia e acolhimento;

- Os alunos sentem-se mais motivados e têm mais interesse em perseguir tópicos que são interessantes para eles. Como resultado, o conteúdo é muitas vezes enraizado em experiências de vida, dando um propósito autêntico para a aprendizagem, conectando-a a um contexto real. Consequentemente, o aprendizado se torna significativo, proposital e mais profundo, resultando em experiências de aprendizagem que permanecem com o aluno durante toda a vida;

- Os estudantes cobrem os tópicos de forma mais aprofundada, porque levam em consideração as diversas e variadas perspectivas a partir das quais um tópico pode ser explorado; as habilidades de pensamento crítico, síntese e pesquisa são desenvolvidas e são aplicáveis a futuras experiências de aprendizagem;

- Todos podem experimentar sucesso e fracasso e os alunos precisam ter sucesso, se quiserem construir confiança e capacidade de assumir riscos e enfrentar desafios cada vez mais difíceis. A habilidade de pensar criticamente é usada e desenvolvida, à medida que os alunos olham através dos limites disciplinares para considerar outros pontos de vista e quando começam a comparar e contrastar conceitos em áreas temáticas (Fung e Howe, 2014);

- Desenvolvimento individual e desenvolvimento de grupo são integrados para que o valor da amizade, confiança e ação conjunta sejam claros. Nesta perspectiva, há competição e também colaboração;

- Tanto a diversidade quanto a inclusão aumentam a riqueza das ideias, o poder criativo, a capacidade de resolução de problemas e o respeito pelos outros; o conhecimento interdisciplinar e a aplicação de diferentes disciplinas podem levar a uma maior criatividade; 
- A aprendizagem do mundo real e as experiências educacionais não se apresentam isoladas e, portanto, devem ser conectadas no cotidiano escolar; os alunos têm oportunidades de consolidar o aprendizado sintetizando ideias, a partir de muitas perspectivas, como uma maneira alternativa de adquirir conhecimento;

- Estudantes e professores são fortalecidos por atos de consequente ajuda aos outros. Os alunos desenvolvem habilidades de colaboração, enquanto trabalham com outras pessoas que tenham diferentes perspectivas. Os professores têm oportunidade de aprender com conexões interdisciplinares, às vezes imprevistas, trazidas pelos alunos;

- $\quad$ Os alunos se tornam pessoalmente envolvidos no seu trabalho, uma vez que lhes é dado o privilégio e a responsabilidade de fazerem escolhas sobre o quê e como aprendem e demonstram a sua aprendizagem;

- Temas interessantes de pesquisa podem "cair" nos "espaços" entre as disciplinas tradicionais, cobrindo "falhas" e conteúdos não abordados;

- O engajamento dos alunos é um desafio para professores e ajudá-los a desenvolver conhecimento, insights, habilidades de resolução de problemas, autoconfiança, autoeficácia e uma paixão pela aprendizagem são objetivos comuns que os educadores trazem para a sala de aula; e a instrução e exploração interdisciplinar promovem a realização desses objetivos (Buchanan, Harlan, Bruce e Edwards, 2016);

- $\quad$ Problemas comportamentais e indisciplinares diminuem naturalmente, quando há interesse, motivação e envolvimento com o assunto abordado (Silva, Negreiros e Albano, 2017).

Foi constatado, também, que trabalhar interdisciplinarmente patrocinou experiências de aprendizagem mais pessoais, relevantes e memoráveis para os professores, que se entusiasmaram com as novas ideias dos alunos e as novas maneiras pelas quais o corpo discente demonstrou sua compreensão. Ficou evidenciado que desenvolver temas através de uma variedade de atividades, ao longo do tempo, tem benefícios específicos para muitos estudantes que, em razão das dificuldades de aprendizagem, podem ter suas experiências limitadas academicamente.

Para os alunos com necessidades de comunicação, os temas permitiram que toda a classe desenvolvesse um vocabulário de conteúdo comum, que eles puderam usar para aprofundar suas interações. Tendo em vista que o ensino de alunos com estas características requer um delicado equilíbrio entre atender as necessidades de aprendizagem e de cuidados específicos, um currículo temático pode fornecer continuidade ao longo do trabalho, facilitando esta tarefa.

É importante salientar que trabalhar na perspectiva da interdisciplinaridade é uma empreitada desafiadora e exigente, tanto para o professor quanto para os alunos; entretanto, também pode ser muito estimulante e gratificante. As condições para desenvolver um trabalho dentro desta natureza vão depender da vontade dos alunos, da instituição e da disponibilidade de recursos do ambiente. Assim, a interdisciplinaridade pode ser algo que a escola queira considerar como uma introdução em todo o currículo, ou algo que o professor experimenta apenas durante pouco tempo, em apenas algumas lições. Seja o que for escolhido, é fundamental tentar envolver, cada vez mais, professores de outras disciplinas. 
As atividades sociais, tais como a homenagem para as mães/tutoras, reúnem as famílias e a equipe da escola, ajudando pais ou responsáveis a ganhar confiança na unidade escolar. A elaboração de relógios e outros trabalhos para a exposição chamou a família para junto da escola, na hora de ajudar as crianças com materiais adequados, com estímulo e ajuda para resolver problemas, mostrando que os pais também assumiram responsabilidade sobre o desfecho do projeto.

Assim, a aprendizagem cooperativa/colaborativa foi percebida e incorporada para além das salas de aula, envolvendo as atividades selecionadas pelos alunos, os detalhes de elementos específicos do projeto, resolução de problemas, desenvolvimento de conscientização sobre as responsabilidades com as tarefas e aprendizado em equipe em ambiente doméstico (Gonzalez, Borders, Hines, Villalba e Henderson, 2013; Jasis e Ordoñez-Jasis, 2012). Observou-se que muitos pais se sentiram à vontade no papel dos coaprendizes. $\mathrm{O}$ os trabalhos patrocinados pelo projeto foram o chamariz que levou os pais a assumirem espontaneamente o papel de, também, professor.

A comemoração de uma data festiva reforçou/promoveu o papel facilitador da família junto aos filhos, independente das habilidades envolvidas nesta facilitação - se eram ajudas especializadas, ou não. Observou-se que os cuidadores procuraram desenvolver seus papéis ativos e de suporte - observando, inspirando, discutindo, explicando, encorajando, etc. Em muitos casos, o simples fato de ajudar a trazer os materiais até a porta da sala estimulava o orgulho e o sorriso dos filhos, promovendo mais estímulo e satisfação para estar em sala de aula, depois que os cuidadores deixavam a escola.

\section{Considerações finais}

O estudo interdisciplinar permite a síntese de ideias e a síntese de características de diversas disciplinas. Ao mesmo tempo, aborda as diferenças individuais dos alunos e ajuda a desenvolver habilidades importantes e transferíveis. Essas habilidades, como o pensamento crítico, a comunicação e a análise são importantes e se desenvolvem continuamente em todas as fases da vida. A escola serve melhor aos alunos, quando ela permite e os encoraja a construir sua própria via interdisciplinar. Este enfoque é seguro para promover o amor pela aprendizagem, inflamar uma fagulha de entusiasmo e abordar as diferenças de aprendizado.

Neste trabalho integrado, os alunos foram vistos como indivíduos inteiros, em vez de exclusivamente no seu papel de aspirantes ao conhecimento em uma única disciplina acadêmica. Foi uma oportunidade de aprendizado em via de mão dupla - para professores e alunos - que foram desafiados a olhar o processo ensino/aprendizagem por ângulos diferentes, saindo dos seus casulos (disciplinas) e englobando, também, os aspectos psicológicos de motivação e bem-estar, decorrentes do engajamento provocado pela oferta de diferentes possibilidades de conteúdos e trabalhos.

A integração foi o cerne deste trabalho interdisciplinar, como é comum em abordagens que sejam multidisciplinares ou temáticas, no contexto de ensinar/aprender. Os alunos examinaram um tópico, através de perspectivas disciplinares distintas, e foram incentivados a reunir conhecimento e habilidades, aprendidas nas diferentes disciplinas, e a aprofundar e enriquecer sua compreensão.

Foi desafiante envolver-se em um processo que levou alunos e professores a evitarem soluções simples e a buscarem o movimento da experiência pessoal atrelada ao 
fazer coletivo, desenvolvendo cada vez mais o pensamento em profundidade, ao se afastarem da concepção tradicional, movendo-se para um sentido mais conceitual, ao compreender a importância do tema e dos trabalhos propostos. Assim, o processo ensino/aprendizagem se tornou muito mais significativo.

Projetos interdisciplinares criam uma conexão entre disciplinas que, de outra maneira, para muitos estudantes poderiam parecer não relacionadas. De forma deliberada, o professor precisa procurar estratégias para conectar-se com conteúdos de outras disciplinas, se quiser trazer experiências verdadeiramente autênticas para o cotidiano da sala de aula, porque no mundo fora dela o conhecimento e os conteúdos não aparecem isoladamente.

As escolas, em sua grande maioria, baseiam seu ensino em disciplinas e devem ter seus objetivos voltados para desenvolver cidadãos, amparados no conhecimento e compreensão das sociedades passadas e presentes. Uma vez que este objetivo de compreender o mundo é uma condição necessária para o exercício racional da cidadania, os saberes adquiridos na escola não estão destinados a permanecem prisioneiros de suas origens escolares e disciplinares. Este conhecimento é uma ferramenta, construída pelos alunos, para ser implementada e utilizada em situações não escolares.

Entender o mundo significa, acima de tudo, compreender os problemas que surgem em nossas sociedades, suas origens, sua complexidade, etc.; também significa aprender e contribuir para resolvê-los. Além disso, os problemas a serem resolvidos não estão essencialmente limitados a um assunto. Se o mundo não é disciplinar, e nem os alunos são, por que o conhecimento deveria ser?

\section{Referências}

Bestelmeyer, S. V., Elser, M. M., Spellman, K. V., Sparrow, E. B., Haan-Amato, S. S. \& Keener, A. (2015). Collaboration, interdisciplinary thinking, and communication: new approaches to $\mathrm{K}-12$ ecology education. Frontiers in Ecology and the Environment, 13, 37-43. doi: 10.1890/140130

Brooks, C. F. (2017). Disciplinary convergence and interdisciplinary curricula for students in an information society. Innovations in Education and Teaching International, 54, 206-2013. doi: 10.1080/14703297.2016.1155470

Bruner, J. (1960). Actual minds, possible worlds. Cambridge, MA: Harvard University Press.

Buchanan, S., Harlan, M. A., Bruce, C. S., \& Edwards, Sylvia L. (2016). Inquiry based learning models, information literacy, and student engagement: a literature review. School Libraries Worldwide, 22, 23-39. Recuperado de: https://eprints.qut.edu.au/102823/.

Danna, M. F. \& Matos, M. A. (2006). Aprendendo a observar. São Paulo: Edicon.

Del-Claro, K. (2004). Comportamento animal: uma introdução à ecologia comportamental. Jundiaí: Conceito, 2004.

DiCamillo, L. \& Bailey, N. M. (2016). Two Teacher Educators Go to the Source: Teaching an Interdisciplinary Class in an Urban Charter High School. The Social Studies, 107, 218-226. doi: 10.1080/00377996.2016.1214904 
Caroni, S. B. (2013). Thinking beyond disciplines: intellectuality, interdisciplinarity, and creativity in Pierre Bourdieu and Umberto Eco. Tese de Doutorado: University College London, Londres. Recuperado de http://discovery.ucl.ac.uk/1393288/1/Sebastia no\%20 Caroni \%20Thesis\%20 Final\%20Draft.pdf.

Cabano, S. (2014). El sueño infantil y el apego. Trabalho de Conclusão de Curso. Universidad de la República, Montevidéu. Recuperado de http://sifp1.psico.edu.uy/el-sue\%C3\%B1o-infantil-y-el-apego.

Fagundes, A. J. F. M. (1999). Definição, descrição e registro do comportamento. $12^{\mathrm{a}}$ ed. São Paulo: Edicon.

Fung, D., \& Howe, C. (2014). Group work and the learning of critical thinking in the Hong Kong secondary liberal studies curriculum. Cambridge Journal of Education, 44(2), 245-270. doi: 10.1080/0305764X.2014.897685

Gruenwald, O. (2014). The promise of interdisciplinary studies: re-imagining the university. Journal Of Interdisciplinary Studies, 26, 1-28. Recuperado de http://connection.ebscohost.com/c/articles/99846009/promise-interdisciplinarystudies-re-imagining-university.

Gonzalez, L., Borders, D., Hines, E., Villalba, J. \& Henderson, A. (2013). Parental Involvement in Children's Education: Considerations for School Counselors Working with Latino Immigrant Families. Professional School Counseling, 16, 185-193. doi: 10.1177/2156759X1701600303

Haynes, C. (2014). Biting into the yellow pepper: The Development of the Interdisciplinary Learner. Issues in Interdisciplinary Studies, 32, 12-27. Recuperado de https://files.eric.ed.gov/fulltext/EJ1117884.pdf.

Huutoniemi, K., Klein, J. T. \& Bruun, H. Hukkinen, J. (2010). Analyzing interdisciplinarity: typology and indicators. Research Policy, 39, 79-88. doi: 10.1016/j.respol.2009.09. 011

Jasis, P. M. \& Ordoñez-Jasis, R. (2012). Latino parent involvement: Examining and empowerment in schools. Urban Education, 47, 65-89. doi: $10.1177 / 0042085911416013$

Lecq, R. (2016). Self-authorship characteristics of learners in the context of an interdisciplinary curriculum: evidence from reflections. Issues In Interdisciplinary Studies, 34, 79-108. Recuperado de https://wwwp.oakland.edu/Assets/Oakland/ais/files-and-documents/Issues-inInterdisciplinary-Studies/vol.

Lenoir, Y., Abdelkrim, H. \& Alessandra, F. (2015). Curricular and Didactic Conceptions of Interdisciplinarity in the Field of Education. A Socio-Historical Perspective. Issues in Interdisciplinary Studies, 33, 39-93. Recuperado de: https://oakland.edu/Assets/Oakland/ais/files-and-documents/Issues-inInterdisciplinary-Studies/volume-33/AISissues15pdf4lenoiretal.pdf.

Mon'im A. A.S. \& Al-Zyoud, M. S. N.A. (2015). Benefits of teaching interdisciplinary subjects collaboratively in Jordanian pre-vocational education. Academic Journals, 10, 2702-2712, 23. doi: 10.5897/ERR2015.2461

Nikitina, S. (2006). Three Strategies for Interdisciplinary Teaching: Contextualizing, Conceptualizing, and Problem-Centering. Journal of Curriculum Studies, 38, 
$251-271$.

Recuperado

de http://www.interdisciplinarystudiespz.org/pdf/Nikitina_Strategies_2002.pdf.

Pharo, E.J., Davison, A., McGregor, H., Warr, K. \& Brown, P. (2014). Using communities of practice to enhance interdisciplinary teaching: lessons from four Australian institutions. Higher Education Research \& Development, 33, 341354. doi: 10.1080/07294360. 2013.832168

Piaget, J. (1969). The theory of stages in cognitive structure. New York: McGraw Hill.

Roberti Jr., J. P., Wilhelm, A. F., Rosa Deon, A. P. \& Collodel-Benetti, I. (2016). Um passeio pela África: práticas pedagógicas significativas no contexto da Lei $\mathrm{n}^{\circ}$ 10.639/2003. Revista Electrónica de Investigación y Docencia (REID),16, 113128 doi: $10.17561 /$ reid.

Sacristán, J. G. (2013). O currículo em ação: os resultados como legitimação do currículo. In: Sacristán, J. G. (org.). Saberes e incertezas sobre o currículo. (pp. 262). Porto Alegre: Penso.

Silva, A. M. P. M., Negreiros, F. \& Albano, R. M. (2017). Indiscipline at public school: Teachers' conceptions on causes and intervention. International Journal of Research in Education and Science (IJRES), 3, 1-10. Recuperado de https://www.ijres.net/index.php/ijres/article/view/130.

Vangrieken, K., Dochy, F., Raes, E. \& Kyndt, E. (2015). Teacher collaboration: A systematic review. Educational Research Review, 15, 17-40. Recuperado de http://daneshyari.com/article/preview/355080.pdf.

Van Rijnsoever, F. J. \& Hessels, L. K. (2011). Factors associated with disciplinary and interdisciplinary research collaboration. Research Policy. 40, 463-472. doi: 10.1016/j.respol.2010.11.001

Vygotsky, L. S. (1984). Mind in society: The development of higher psychological processes. Cambridge: Harvard University Press.

\footnotetext{
i Na concepção desta escola e desta comunidade, esta é uma comemoração realizada para os pais/responsáveis/ cuidadores/tutores, oriundos das mais diferentes configurações familiares, não se restringindo apenas à mãe biológica, ou aos pais heterossexuais.

ii No sistema escolar brasileiro, quando os alunos se mantêm academicamente sem reprovações e atrasos, a idade certa para frequentar o $5^{\circ}$. Ano (Ensino Fundamental I) é 10 anos e o $8^{\circ}$. Ano (Ensino Fundamental II) é 13 anos.

iii A frase é finalizada com o horário de nascimento de cada aluno-participante. Tradução: "Eu nasci às... (X horas)".
}

Data de recebimento: 07/08/2017

Data da revisão: 01/06/2018

Data do aceite: 13/06/2018 